\title{
Por um fazer marginal: a questão marioandradina e a fatura oswaldiana da poética de Cacaso
}

\author{
Towards a marginal means: Mário de Andrade's question \\ and Oswald de Andrade's solutions in Cacaso's poetics \\ Por un hacer marginal: la cuestión marioandradina \\ y la factura oswaldiana de la poética de Cacaso
}

Lucius Provase*

\section{Resumo}

As relações entre a poesia marginal e a poesia modernista de 22 são um clichê crítico na pequena fortuna crítica que se formou sobre os poetas dos anos 1970. A proposta deste artigo é debruçar-se sobre o que de fato há de modernista nessa poesia dos anos 1970. Tomaremos as relações entre a crítica e a poesia de Cacaso, do lado da poesia marginal, e as estéticas de Mário e Oswald de Andrade, do lado modernista, para apontar as semelhanças e diferenças existentes entre marginais e modernistas.

Palavras-chave: Cacaso, poesia marginal, poética.

\begin{abstract}
The relationship between the so-called "marginal" poetry and the modernist poetry of 1922 is a frequent cliché within the small but prolific critical reception of the poets of the 1970s. The purpose of the article that follows is to establish what is actually modernist in the poetry of the 1970s. We adopt the relationship between Cacaso's criticism and poetry on the side of "marginal" poetry, and the aesthetics of Mario de Andrade and Oswald de Andrade on the modernist side, to point out the similarities and differences between the "marginal" and the modernists.
\end{abstract}

\begin{abstract}
Resumen
La relación entre la llamada poesía "marginal" y la poesía modernista de 1922 es un cliché crítico sobre la fortuna crítica de los poetas de los años 1970. El propósito del artículo que sigue es asomarse a lo que en realidad hay de modernista en la poesía de los años 1970. Vamos a tomar la relación entre la crítica y la poesía de Cacaso, del lado de la poesía "marginal", y la estética de Mario y de Oswald de Andrade, en el lado modernista, para señalar las semejanzas y las diferencias entre marginales y modernistas.
\end{abstract}

Palabras clave: Cacaso, poesía marginal, poética.

Keywords: Cacaso, marginal poetry, poetics.

\section{O marginal, os modernistas e a escrita rarefeita}

Há um poema de Cacaso que representa bem a visão geral que se tem sobre a poesia marginal. O poema chama-se "Na corda bamba", do livro de 1978, de mesmo nome (Figura 1).

A começar pelo título, analisado por Heloísa Buarque mais a frente, passando pela dedicatória e pela relação arte e vida, o poema brinca com as diversas situações enunciativas presentes no texto. Passamos do mundo da experiência, para o mundo da construção, atravessamos as relações pessoais do poeta por meio da dedicatória, saímos da escrita para a fala sem nunca repousar em uma dessas diversas instâncias. A poesia, não o poema, é vivida, e não escrita. No entanto, lá está o poema, não a poesia, escrito, contrariando o que se anuncia. Criada a tensão, espera-se uma solução deixada para a última estrofe com apenas um verso.

\footnotetext{
* Doutor em Letras e pós-doutorando em Letras na Universidade Federal do Paraná (UFPR), Curitiba, PR, Brasil. (Dorcid.org/00000003-2030-7299. E-mail: luciusp@uol.com.br.
} 
Encontramos, contudo, uma saída pela tangente: a resolução para essa questão não está no poema, ao menos não em nenhuma das situações enunciativas criadas por ele. O último verso joga o poema para uma outra enunciação.

\title{
NA CORDA BAMBA
}

\author{
p/ Chico Alvim
}

\section{POESIA}

EU NAO TE ESCREVO

EU TE

VIVO

E VIVA NOSS :

Figura 1 - Poema "Na corda bamba". Fonte: Brito (1978). Foto: Lucius Provase.

O texto seria representativo da leitura crítica corrente sobre a poesia dos anos 1970, que a associa às práticas de escrita voltadas antes à expressão do que à reflexão, textos que buscavam apenas cristalizar o momento, uma espécie de "versão hedonista do processo discriminatório da modernização brasileira" para retomar as fortes palavras do conhecido ensaio "Poesia ruim, sociedade pior", de Iumna Simon e Vinicius Dantas (1985, p. 57); um uso ultrapassado, histórica e tecnicamente, de procedimentos modernistas, principalmente a coloquialidade, que não mereceria uma aproximação mais cuidadosa. Ainda segundo os críticos, em uma leitura que poderia ser dirigida ao poema acima:

nos poemas dessacralizados compõe-se um painel caótico e banal do cotidiano que é a imagem da dessacralização geral de um mundo igualmente caótico e absurdo. Só que fica difícil discernir no valetudo dessa sensibilidade se os poemas são menos banais que o mundo que os inspirou (Simon e Dantas, 1985, p. 57).

Se é para retratar uma realidade banal de forma banal, qual o sentido do poema? A experiência não seria sempre superior ao seu retrato? A força da leitura desses críticos é "enfiar o dedo na ferida", é cutucar o ponto frágil da produção poética dos anos 70 ao questionar a validade da escrita se igualada à própria experiência.

A mesma questão reaparece em Heloísa Buarque, que propõe uma leitura em outra chave do poema rápido e rasteiro:

que a aparente gratuidade proposta no poema coloca em pauta a contradição que inevitavelmente se esboça quando nos aproximamos de um poema "autenticamente marginal". Ou seja, quando o poeta marginal propõe uma quase coincidência entre poesia e vida, essa proposta poderia, no limite, resultar no desaparecimento da própria poesia. É a produção poética literalmente "na corda bamba" (que aliás dá nome não apenas ao poema, mas também ao livro), na qual o poeta marginal consegue equilibrar-se quase sempre com alguma dificuldade. Um caminho difícil e conflituado que pode ser entrevisto na própria trajetória da obra poética de Cacaso (Hollanda, 2002)

Uma negação da própria poesia, ou sua impossibilidade diante do impasse que se coloca entre experiência e construção, entre vida e arte, essa é a leitura proposta para o poema. O clímax dessa relação tensa entre esses elementos seria o enfraquecimento da palavra escrita. 
No que concerne ao Cacaso, ao menos em seus textos mais maduros, há um impasse entre fala e escrita, experiência e literatura, expressão e construção. Todos binômios que representam a mesma relação, maneiras diferentes de se aproximar de uma mesma questão, a saber, a relação entre arte e vida: uma questão que reaparece com frequência na literatura brasileira, sendo trabalhada também pela crítica das maneiras mais distintas.

Antes de avançarmos, é preciso compreender a trajetória que levou a essa rarefação da escrita; em nosso entendimento, a compreensão passa pelos primeiros modernistas, pois a presença destes se dá não apenas no poeta Cacaso, através da referência a determinados procedimentos poéticos, mas no crítico Cacaso, através da leitura atenta de escritores como Mário de Andrade, Manuel Bandeira e Oswald de Andrade. Combinando essas duas aproximações, acreditamos ser possível melhor compreender as reflexões sobre a escrita que aparecem nos textos do escritor mineiro.

\section{Um leitor dos modernistas: em busca da liberdade}

Antônio Carlos de Brito era não apenas um escritor, mas professor universitário e pesquisador ativo, participando de diversos grupos de estudo com outros escritores, alunos, amigos. Fazia do exercício teórico parte do seu trabalho criativo; Charles Peixoto, em entrevista concedida a Heloísa, afirma que era Cacaso quem dava seriedade à produção daquela geração, justamente através da teorização do movimento. O papel de teórico da geração dado a ele é aceito de forma unânime por outros poetas. Para exemplificar, ${ }^{1}$ um trecho da entrevista para o site de Heloísa Buarque:

HBH: Acho que Cacaso marcava uma posição claramente diferenciada também porque era antes de mais nada um aglutinador. Ele conseguia transitar quase naturalmente entre os muitos grupos daquele tempo, articulando projetos, coleções e até "explicando" para os poetas o que eles estavam fazendo.

CPC: Isso era muito engraçado. Cacaso era o nosso teórico. A gente ficava pasmo com o que ele dizia sobre a gente. Cacaso tinha o personagem do professor. Guilherme Mandaro foi o nosso primeiro professor, mas se suicidou cedo, logo no começo. Cacaso instigava a produção. Ele interpretava o que a gente escrevia, dava seriedade na coisa e isso fazia a gente não abandonar o barco (Hollanda, 2002).

O que o poeta Charles Peixoto chama de "dar seriedade para a coisa" é a busca de Cacaso por um lugar no campo literário para a poesia marginal. Esse processo passa pelo modernismo. E são nos ensaios, na produção teórica, que se encontram as referências mais claras e explícitas sobre a produção modernista; nos ensaios podemos perceber de que modo o poeta e crítico mineiro recebia a produção daqueles escritores de 22, principalmente a ensaística de Mário de Andrade. É nos ensaios que percebemos que a leitura que Cacaso faz da escrita modernista é uma forma de validar sua própria obra e dar a ela algum tipo de lastro, uma filiação que não se limite apenas à cópia de coloquialismos, ironias e outros procedimentos. Cacaso busca nos modernistas a justificativa para a sua busca pela liberdade da escrita.

O sentido que Antônio Carlos de Brito dava à palavra liberdade pode ser inferido a partir de um ensaio bastante interessante sobre Mário de Andrade. O texto é uma espécie de resenha crítica/ensaio, de 1978, sobre o livro O banquete de Mário. Nesse livro, o modernista discute algumas questões estéticas, muitas ligadas à música, mas cujas reflexões servem também à literatura. Uma em particular serve de mote para todo o ensaio: a relação entre o modernismo e o que eles, os modernistas, chamavam de academismo. Surge uma interpretação interessante de Cacaso sobre a crítica que Mário de Andrade faz aos academistas:

Segue-se, nas palavras do virtuose, que 'a maior conquista do modernismo brasileiro foi sistematizar no Brasil, como princípio mesmo da arte, o direito de errar'. Vê-se, por aí, que

\footnotetext{
${ }^{1}$ Além de Charles Peixoto, há ainda o depoimento de Carlito Azevedo na revista Inimigo Rumor número 8, o reconhecimento do papel exercido por Cacaso pelo crítico Carlos Messeder no livro Retrato de Época, entre outros depoimentos, incluído aí a famosa frase de Paulo Leminski, pronunciada após um encontro de poetas: "nenhum lance de dados abolirá o Cacaso".
} 
o problema do academismo não é propriamente acertar, mas acertar sempre, e para tal é levado a abolir não o erro, mas a sua simples possibilidade, e daí só pisar em terreno bem firme e já provado. E daí a rotina inevitável (Brito, 1997, p. 159).

$\mathrm{O}$ escritor mineiro procura compreender o que seria a situação da literatura contemporânea, partindo da leitura de Mário de Andrade. Os acadêmicos de Cacaso seriam a geração de $45 \mathrm{e}$, principalmente, os concretos:

O concretismo vai abolir o direito de errar, expressão da insuficiência da linguagem, mas que leva à inovação e ao experimento, pela supressão pura e simples do contexto onde tudo isso ocorria: a palavra versificada, mas sobretudo a livre expressão, o verso livre. Surge uma concepção de experimento curiosa, onde o risco da criação dá lugar à fixidez da regra, a insuficiência à plenitude, o questionamento à quase idolatria (Brito, 1997, p. 164).

A oposição ferrenha de Cacaso à geração anterior explica-se porque o poeta mineiro enxergava nesses escritores uma quebra das grandes conquistas do modernismo. Mas o que seria “experimentar" no entendimento do escritor dos anos 1970? Segundo sua leitura do romantismo e do modernismo, havia, nesses movimentos, "a dissolução de regras, a quebra de hierarquias, planos embaralhados, valores subvertidos, tudo aquilo que configura a modificação e o questionamento profundo da fisionomia estabelecida do discurso" (idem, ibidem). Mais do que isso. Abrir mão do direito de errar é abrir mão da arte.

O direito de errar, que tem como consequência direta a pesquisa e a inovação, não é desculpabilidade ou justificativa para o erro, enquanto imperícia contingente deste ou daquele artista, mas é a recuperação da sua possibilidade como parte e condição mesma do fazer artístico (Brito, 1997, p. 159).

Aproximar-se do modernismo de 22 mostra dois movimentos: validar a leitura que é feita por Antônio Carlos de Brito do momento histórico no qual ele vive; afastar-se de outros movimentos literários, como o concretismo, invalidando-os. Podemos inferir, embora isso não seja dito de forma explícita em nenhum momento, nem mesmo em outros textos, que Cacaso roga a si mesmo e, provavelmente, a alguns de seus contemporâneos, o papel de continuadores do modernismo. Há que se entender "continuadores" no sentido de fazerem da experimentação o motivo mesmo da construção artística. Dito de outro modo, não existe a intenção de continuar o projeto modernista, muito pelo contrário. Em outros escritos críticos podemos perceber que não há mais espaço para a construção de projetos, o que se faz necessária é a elaboração de um espaço discursivo que questione "a fisionomia estabelecida do discurso" (Brito, 1997, p. 159). Dito de outra forma, o modernismo que Cacaso vê como linha de fuga para a poesia marginal não é o mesmo modernismo "diluído" em poemaspiada, instantaneidade, focado no acontecimento cotidiano, que comumente é associado a muitos escritores e escritoras da poesia marginal de 1970; o modernismo que Cacaso, poeta, aponta como caminho é este que ele procura sistematizar como teórico.

Parece, portanto, que a ponte que deve ser feita entre o modernismo de 1922 e Antônio Carlos de Brito não deve buscar as óbvias semelhanças entre esses dois momentos poéticos, mas as diferenças, não apenas históricas, no aproveitamento da matéria poética, da matéria escrita ela mesma. O "confronto direto" entre o poeta dos anos 1970 e o modernismo pode ajudar a revelar ainda mais do que fica apenas esboçado nesses textos críticos: a necessidade de liberdade coincide com a necessidade de se criar um espaço discursivo livre. Nada poderia ser mais óbvio do que reforçar o caráter livre, ligado ao experimentalismo, da arte, em um momento de grande repressão.

Provavelmente, haverá um questionamento acerca do que escrevemos até aqui: em que momento a presença dos modernistas pode ser vista num texto como o que analisamos? Que lição exatamente foi apreendida dos modernistas? O que procuramos mostrar, ainda que brevemente, é que o poeta mineiro tomará como lição máxima dos modernistas a busca pela liberdade, o experimentalismo.

Justamente na busca pela liberdade é que aparecerá a instabilidade, que mencionamos na leitura do poema "Na corda bamba", entre escrita e fala, expressão e construção. Talvez seja essa 
instabilidade, aliada a busca pela liberdade, que o tenha levado a optar, ao final de sua vida, pela canção, ${ }^{2}$ uma forma que leva ao limite essa relação. De qualquer modo, o próximo passo é atar a outra ponta desse diálogo entre Cacaso e os modernistas, menos explícita, mas certamente não menos importante: a relação arte e vida.

\section{A relação entre arte e vida no modernismo: Mário de Andrade}

Se Cacaso era leitor atento dos modernistas, Mário de Andrade foi uma grande referência para ele, sobretudo na oposição explícita que o primeiro fazia aos concretos e à geração de 45 . Usou não apenas uma atitude diante da literatura, mas a percepção do fenômeno literário mesmo como fio condutor. Daí decorre a postura de Cacaso diante da arte e da vida.

Impossível afirmar que foi Antônio Carlos de Brito quem propôs a leitura da relação entre arte e vida para a poesia marginal. Até porque, dois anos antes da publicação de seu primeiro livro de poesia marginal, o Grupo escolar, já haviam sido publicados outros livros com uma temática marginal, ${ }^{3}$ os quais despertaram a atenção da crítica para uma curiosa revitalização da poesia. Faremos, contudo, a suposição de que Cacaso vai aproveitar essa relação para imprimir um viés teórico que lhe era caro, teorizando a poesia marginal a partir de uma perspectiva modernista.

Mais uma vez Mário de Andrade será a referência principal, mas não única, no quesito arte e vida. É notório o interesse do poeta paulistano pelas relações entre lírica e técnica; são muitos os textos nos quais ele se debruça sobre o que chama de psicologia do escritor. Dito de outro modo, não é preciso buscar com lupas para encontrar diversas referências sobre a relação entre arte e vida, entre o que Mário chama de expressividade, lírica, psicologia e entre o que chamava de construção, técnica. Se tomarmos o famoso "Prefácio interessantíssimo" e seu correlato "A escrava que não é Isaura", encontraremos a fórmula: lirismo + arte = poesia, sendo que arte é entendida como trabalho; o esteticismo e lirismo, por outro lado, vêm da necessidade de expressão. A fórmula aparece em ambos os textos e parece refletir a preocupação de Andrade em dar credibilidade ao então incipiente modernismo. A preocupação, contudo, da relação entre a expressão e construção, uma das muitas faces da relação arte e vida, é constante.

Em ensaios posteriores Mário de Andrade mostra reflexões com o mesmo teor, mas mais atentas aos exageros e a possíveis falhas. Um exemplo, retirado do "Elegia de abril":

Nós éramos abstencionistas, na infinita maioria. Nem poderei dizer 'abstencionistas', o que implica uma atitude consciente do espírito: nós éramos uns inconscientes. Nem mesmo o nacionalismo que praticávamos com um pouco maior largueza que os regionalistas nossos antecessores, conseguira definir em nós qualquer consciência da condição do intelectual, seus deveres para com a arte e a humanidade, suas relações com a sociedade e o estado (Andrade, 1978, p. 186).

O já famoso livro de Lafetá, 1930: a crítica e o modernismo, analisa muito bem essa postura de Mário, ao discordar de algumas leituras que Roberto Schwarz realiza no ensaio "O psicologismo de Mário de Andrade". Retomaremos a citação do texto de Schwarz, na qual ele comenta alguns pontos básicos de "A escrava que não é Isaura", para a seguir incluir a "resposta" de Lafetá.

Voltando: a descoberta do menino Rimbaud tem consequências imediatas: a poesia deve ser a pura grafia do lirismo, despido de qualquer impedimento de ordem material ou intelectual; versos e rimas devem ser livres, a lógica não tem que ditar normas. O tema, que é uma delimitação lógica dentro do campo mais vasto do assunto, deve desaparecer. Os movimentos da subconsciência devem ser inteiramente respeitados. Mesmo as resistências do medium expressivo, a linguagem estruturada, devem ser rompidas - inventem-se

\footnotetext{
${ }^{2}$ Cacaso exerceu durante muito tempo o papel de letrista e não apenas ao fim de sua vida. Queremos dizer que ao final da vida, ele buscava viver apenas como letrista.

${ }^{3} \mathrm{O}$ que chamamos aqui de "temática marginal" não é referência apenas aos tópicos comuns à poesia marginal, mas a um conjunto de formas de dizer. Aos tópicos, sempre um recorte de uma situação do cotidiano, somam-se uma exposição em forma de retrato ou ready-made (para tomar expressão que usarei adiante) dessa situação. Para retomar a linguagem que utilizamos aqui, é o trabalho com o deslocamento das cenas de enunciação que marca essa temática: as cenas de enunciação de subjetividade em Ana Cristina César; as cenas do cotidiano, no caso de Chacal, Francisco Alvim e do próprio Cacaso.
} 
neologismos e sintaxes. A linguagem é pura serviçal do subconsciente e deveria, para coerência absoluta, anular-se de uma vez (Schwarz, 1965, p. 4).

Antes das objeções de Lafetá, cabe ressaltar as semelhanças entre as ressalvas que Schwarz faz à postura teórica de Mário de Andrade, e as observações que Simon e Dantas fazem sobre os poemas marginais no ensaio que orientou a leitura. No limite, essa prevalência da lírica sobre a técnica, da experiência sobre a construção, só pode levar a uma linguagem nula, posto que subserviente ao subconsciente, ao imediatismo: "Essas seriam sem dúvida as consequências da predominância do lirismo, caso fosse levada até os seus limites finais. Mas tal não se dá: o 'lirismo' está relacionado em tensão com a 'arte', não se encontra em oposição irredutível” (Lafetá, 2000 p. 173).

O crítico ainda ressalva que essa afirmação pode ser facilmente encontrar no próprio "Escrava", ensaio no qual Mário de Andrade afirma que "lirismo não é poesia" e Lafetá complementa

E não o é por faltar a arte, por faltar o procedimento especificamente estético, a organização do moto lírico. A técnica é uma complementação necessária do lirismo, Mário de Andrade o sabe perfeitamente; por isso, também jamais afirmaria que os 'movimentos da subconsciência devem ser inteiramente respeitados', nem que 'versos e rimas devem ser livres', se tomarmos aí a palavra 'livres' no sentido absoluto que Roberto Schwarz parece lhe atribuir: a teoria do 'polifonismo' constitui uma sistematização que, embora justificada psicologicamente, possui um estatuto estético indiscutível, na medida em que é vista como uma processo de organização estrutural do poema (Lafetá, 2000, p. 174).

Lafetá ressalta ainda a passagem de um binômio lirismo/arte para o trinômio lirismo/arte/sociedade, citando ensaios como "Elegia de abril", "A poesia em 1930" e outros ensaios do livro Aspectos da literatura brasileira. O debate em muito se assemelha ao que se cristalizou em torno da poesia marginal. As colocações de Schwarz parecem com aquelas de Simon e Dantas, assim como a leitura de Lafetá lembra a leitura de Heloísa Buarque. Não deixa de ser curioso notar que pouco avanço houve na discussão de uma temática tão importante para a literatura brasileira quanto a relação entre arte e vida. Ainda mais curioso é que o debate sobre a literatura modernista ocorria no momento mesmo em que acontecia o fenômeno que ficou conhecido como poesia marginal.

De qualquer modo, não é nosso interesse discutir a pertinência das informações, mas apontar leituras, sobre as quais podemos supor que Cacaso, como professor de Teoria Literária e amigo de Roberto Schwarz, tenha tido acesso. Além disso, é possível afirmar que os dois críticos, Schwarz e Lafetá, principalmente o último, sintetizam, em seus textos, percepções que ressoam até os dias de hoje sobre a poesia modernista. Por esse motivo mesmo, destacaremos um elemento presente nesses ensaios de Mário e que não apareceu como elemento no debate: a liberdade, ou melhor, a busca pela liberdade.

Há diversos textos, entre cartas, ensaios e poemas, nos quais a preocupação com a liberdade aparece em Mário. A palavra é utilizada em diferentes acepções, como no prefácio interessantíssimo:

Minhas reivindicações? Liberdade. Uso dela; não abuso. Sei embridá-la nas minhas verdades filosóficas e religiosas; porque verdades filosóficas, religiosas não são convencionais como a Arte, são verdades. Tanto não abuso! Não pretendo obrigar ninguém a seguir-me. Costumo andar sozinho (Andrade, 1980, p. 22).

Aqui a liberdade é vista como um direito do indivíduo; é algo que não se impõe e com o qual se deve ter cuidado, posto que em excesso possa escapar à própria Arte. O problema que decorre dessa postura será percebido por Mário de Andrade anos mais tarde e será visto por muitos modernistas, da primeira e da segunda geração: o excesso de liberdade individual levou ao que ele chama de abstencionismo. Essa postura, como o próprio escritor paulista percebe mais tarde e como salienta Schwarz, pode levar a escrita ao silêncio.

A busca pela liberdade é um outro ponto de intersecção entre Mário e Cacaso, por isso nosso interesse. Contudo, nesse ponto em especial, o modernista parece não ter encontrado o equilíbrio entre os elementos que compõem a equação, ainda que ciente de todos os problemas que poderiam surgir, já que, ao que parece, nem sempre lirismo + arte = poesia, como o próprio Antônio Carlos de Brito percebe em alguns de seus escritos sobre a poesia dos anos 1970. 


\section{Oswald}

Outro escritor modernista para o qual a relação entre a arte e o cotidiano se mostra importante é Oswald de Andrade. É famoso o trecho do "Manifesto Pau-Brasil" que professa: "A poesia está nos fatos", mais do que isso: "os casebres de açafrão e de ocre nos verdes da Favela, sob o azul cabralino, são fatos estéticos" (Andrade, 1997, p. 326). É esse o parágrafo que abre o manifesto, que pode indicar uma defesa de uma poesia expressiva, algo reforçado pela adjetivação exagera, ligada mais à experiência vivida do que à técnica. Porém, alguns parágrafos abaixo, lemos o seguinte: "O trabalho contra o detalhe naturalista - pela síntese; contra a morbidez romântica - pelo equilíbrio geômetra e pelo acabamento técnico; contra a cópia, pela invenção e pela surpresa" (Andrade, 1997, p. 329). O que vemos é uma posição ambígua, característica de Oswald em seus escritos, no que concerne ao papel da poesia na relação com a vida. O que em Mário de Andrade é lirismo, passando pelo filtro da objetividade oswaldiana, vira cotidiano.

Assim como acontece com Mário de Andrade, há um embate interessante entre dois ensaístas e, novamente, a presença de Roberto Schwarz. Estamos falando de Haroldo de Campos, com o seu "Poética da radicalidade" e "A carroça, o bonde e o poeta modernista", do crítico de Ao vencedor as batatas. Nesses dois ensaios temos os dois polos de um espectro crítico, no qual outros estudiosos de Oswald vão se inserindo. ${ }^{4}$ De um lado, um poeta que trabalha expandindo limites, estabelecendo diálogos com outras artes, trazendo novos patamares para o fazer poético; do outro, um poeta que tropeça em seu próprio projeto. A diferença pode ser vista na abertura dos textos, os quais apresentam a visão sobre a poética do poeta modernista, desenvolvendo-a no decorrer dos respetivos ensaios.

Schwarz coloca a questão da seguinte maneira:

Oswald de Andrade inventou uma fórmula fácil e poeticamente eficaz para ver o Brasil. A facilidade no caso não representava defeito, pois satisfazia uma tese crítica, segundo a qual o esoterismo que cercava as coisas do espírito era uma bruma obsoleta e antidemocrática, a dissipar, fraudulenta no fundo (Schwarz, 1987, p. 11).

A fórmula seria "a justaposição de elementos próprios ao Brasil-Colônia e ao Brasil burguês, e a elevação do produto - desconjuntado por definição - à dignidade de alegoria do país" (Schwarz, 1987, p. 12.) Haroldo, por sua vez, coloca-se contra a ideia de fórmula "Se quisermos caracterizar de um modo significativo a poesia de Oswald de Andrade no panorama de nosso Modernismo, diremos que esta poesia responde a uma poética da radicalidade. É uma poética radical" (Schwarz, 1997, p. 7). A radicalidade do poeta modernista residiria

no campo específico da linguagem, na medida em que esta poesia afeta, na raiz, aquela consciência prática, real que é a linguagem. Sendo a linguagem, como a consciência, um produto social, um produto do homem como ser em relação, é bom que situemos a empresa oswaldiana no quadro de seu tempo (Campos, 1971, p. 7).

A empreitada oswaldiana é marcada pela ambiguidade. Muito dessa postura de Oswald de Andrade, dessa busca por novos materiais, vem da necessidade pelo novo. Por outro lado, há o artista que trabalha e reescreve o texto de maneira "flaubertiana" para retomar a comparação de Vinicius Dantas. É do mesmo crítico uma observação que bem resume a inconstância e a consequente incoerência de Oswald quanto ao trabalho com a escrita:

de início, o texto é posto em banho maria por um artista flaubertiano, doentiamente empenhado no brilho da frase, amigo das excelências da fatura; mais tarde, por uma circunstância qualquer e com afobamento, tudo é desmanchado e o texto oswaldiano vem a lume prematuro (!). O criador que se aplicara durante meses a fio a aprimorar um

\footnotetext{
${ }^{4}$ Ao dizermos que os outros críticos se inserem em um espectro crítico, não queremos desmerecer o trabalho de estudiosos de Oswald de Andrade do porte de Maria Augusta Fonseca e Vinicius Dantas, pois ambos contribuíram muito para melhor compreensão da obra do poeta modernista, produzindo ensaios anteriores aos mencionados. Nossa posição indica apenas que, pelo fato dos textos lidarem com o sucesso e o fracasso de uma poética, de maneira bastante incisiva e sem espaços para ponderações, os críticos acabaram por se inserir nessa batalha.
} 
estilo, rendia-se ao fogo de palha de uma experiência fresca, vivida anteontem. Se o caso da mencionada re-escrita das Memórias Sentimentais é desse tipo, o que dizer do capítulo "Os Antropófagos" de Serafim Ponte Grande, enfiado às pressas em livro concluído, à maneira de um epílogo post-mortem? A invenção oswaldiana não se ressentiu dessa política de extremos, antes pelo contrário e surpreendentemente lhe deve o que possui de melhor (Dantas, 1991, p. 200).

A presença da experiência cotidiana como matéria da poesia oswaldiana também é fruto dessa ambiguidade de um escritor que percebe o Brasil em Paris. Parece claro que a relação entre arte e vida nos textos oswaldianos tem um caráter diferente do que assume nos textos de Mário de Andrade: ela não faz parte de uma reflexão sobre o estatuto da arte, mas está ligado a uma prática da escrita. Obviamente isso não quer dizer que não há prática em Mário ou que Oswald não exerça teoria, quer dizer apenas que há uma diferença de postura diante da arte. Cacaso parece combinar essas duas posturas. Não foge de teorizar e refina sua teoria pela prática. Ou seja, a questão é marioandradina, mas a fatura é oswaldiana.

\section{Arte e vida em Cacaso}

A relação arte e vida em Cacaso é quase um dado crítico. A fortuna crítica de Cacaso e da poesia marginal como um todo coloca que essa volta ao cotidiano, ao coloquialismo é uma resposta ao ambiente cultural e uma rejeição da literatura anterior, sobretudo o concretismo e a geração de 45. Ou seja, o clima de antiarte pairava sobre diversas manifestações artísticas, e a recusa da geração de 45 e dos concretos era manifestada claramente por críticos e poetas ligados ou não à poesia marginal.

Um dado que não aparece com frequência, contudo, é o viés modernista que existe nessa postura, tratando de Cacaso, e que tentamos mostrar até aqui. Os modernistas aparecem na fortuna crítica como referência para certos procedimentos literários, mas não como referência teórica, algo que, como mostramos, certamente eram. Por isso, nos centraremos em como se dá a presença modernista, a partir do que vimos nos itens anteriores, para analisar a relação entre arte e vida, a qual serve de base para a busca pela liberdade para a escrita.

Essa progressão foi mostrada no início do texto: Cacaso vê na relação arte e vida, tal qual estabelecida pelos modernistas, uma porta para a sua própria busca pela liberdade. ${ }^{5} \mathrm{O}$ cuidado com um elemento como esse, que significa autonomia para a arte, mas não só isso, parece bastante claro em um contexto de repressão. Por esse motivo, há claras diferenças nas posturas de Cacaso e dos dois Andrades: o poeta dos anos 70 não é nem tão objetivo nem tão lírico no tratamento da matéria experimentada; a crença no progresso já tinha sido vencida, como também foi vencida a construção de um projeto de nação; além disso, há o já citado campo cultural.

O fato é que extrairemos dos escritos de Cacaso essa relação. Um primeiro exemplo pode ser colhido ao nos debruçarmos sobre dois textos em que poetas de destaque nos anos 1970, Chacal e Chico Alvim, são avaliados a partir da aproximação entre a poesia e a vida, entre o poético e o cotidiano. Trabalhada na poesia marginal, essa relação não transformou a poesia "em um veículo acrítico e desqualificado de expressão" (Simon e Dantas, 1985, p. 48) Obviamente há diferença no alcance crítico não só entre esses dois poetas, mas também entre Cacaso e ambos os poetas. O procedimento geral, contudo, é bastante semelhante.

Comecemos com um trecho de um poema de Chacal:

BUNDA MOLE DEDO-DURO TANTO TREME QUANTO ENTREGA (apud Brito, 1997, p. 32)

Cacaso descreve o procedimento utilizado nesse trecho da seguinte maneira:

\footnotetext{
${ }^{5}$ Não se trata, importante destacar, de falar de modernismo a partir dos procedimentos, mas da maneira como as escolhas de Cacaso são um diálogo constante entre o que ele vê como princípios teóricos do modernismo e o que ficou marcado como procedimento modernista: o poema curto, a linguagem coloquial, a crítica ao academismo e uma dessacralização, ainda que contida, do que seria a poesia e o poético.
} 
É fácil saber de que água Chacal bebeu: 'água mole em pedra dura...' etc. O ditado popular, com sua característica frase feita, seu tom moralizante e alegórico, é devorado e transformado noutro ditado, com outro raio de intenção, visando a outras imagens, num tom radical e de efeito desmoralizante. Que tipo de crítica é essa? De onde provém seu alcance? (Brito, 1997, p. 32).

A conclusão, resumindo os argumentos que se seguem à citação acima, é que há, na poesia de Chacal, um descompromisso e uma informalidade poética que resultam em uma atitude crítica. Interessa-nos, antes, o procedimento já que, como dissemos, o alcance crítico da poesia de Chacal é questionável e cabem algumas das críticas que Simon e Dantas fazem à poesia marginal: "dispõe formalmente seus elementos: o registro confessional e biográfico, a anotação irreverente do cotidiano, a nota bruta do sentimento, da sensação, do fortuito, são soluções poéticas que acabam impondo um padrão informal e antiliterário 6 de estilização" Simon e Dantas, 1985 , p. 54). Dito de outro modo, o bom resultado poético não é garantido pela simples reprodução da experiência, pois, muitas vezes, acaba por tornar-se simples procedimento estético, já que desacompanhado do movimento crítico. O próprio Cacaso reconhece essa possibilidade, no mesmo texto:

Esta informalidade que hoje reina em setores importantes de nossa ideologia de resistência, em nossa multiforme contracultura, facilita a difusão e a aceitação da crença de que uma vez que fazer arte e viver já não se distinguem, então a possibilidade de criar também já não supõe maiores capacitações, e todo mundo indistintamente é promovido a artista, o que é o mesmo que extinguir a espécie (Brito, 1997, p. 28).

A observação não é feita especificamente sobre os textos de Chacal, mas podemos colher exemplos no texto que demonstram que a liberdade que Cacaso celebra, a relação a arte e vida não é simplesmente individual: "estamos diante de uma atitude de desabafo e o valor do poema passa a depender menos da realização do que da sinceridade - valor moral- que manifesta"; ou ainda "temos a impressão de que o poema fica aquém da complexidade de tratamento que sua matéria solicita" (Brito, 1997, p. 38). Por fim, o crítico dá um exemplo de sua concepção de liberdade: "a liberdade é para ser encarnada agora e não para ser uma meta futura, como na poesia missionária de esquerda, ou simplesmente sufocada e administrada, como nos autointitulados grupos de vanguarda" (Brito, 1997, p. 43). A oportunidade de, mais uma vez, usar a discussão sobre a liberdade para se afastar de outros tipos de poesia não é desperdiçada.

A percepção geral de Cacaso quanto aos textos de Chacal é que, entre erros e acertos, a vitória é da liberdade conquistada pela relação poesia e vida. O crítico parece supor a fragilidade desses textos e termina assim seu artigo:

Sobre o valor propriamente literário da poesia de Chacal, a questão do seu envelhecimento ou duração, sua importância e lugar dentro do quadro mais geral de nossa poesia, tudo isso depende em parte de perspectiva temporal, o que não nos é possível por agora (Brito, 1997, p. 43).

Movimento diferente é realizado na leitura de parte considerável da poesia de Francisco Alvim. O movimento crítico é completo e também recebe a atenção de Cacaso. Tomemos como exemplo a análise que é feita do seguinte poema de Alvim, do livro Passatempo, de 1974:

Almoço

Sim senhor doutor, o que vai ser?

Um filé mignon, um filezinho, com salada de batatas

Não: salada de tomates

E o que vai beber o meu patrão?

Uma caxambu (Alvim, 1988, p. 221)

A citação é longa, mas explicativa:

O segredo de um poema como este parece estar na quantidade de experiência que acumula, algo que surge na forma de hábito formado, de costume. Como no gesto social

\footnotetext{
${ }^{6}$ Não há precisão no que os dois críticos querem dizer com "antiliterário". Parece ser apenas uma confirmação das leituras feitas até então sobre a poesia marginal, com o valor invertido; ou seja, negativo.
} 
do garçom, simpático, mas também submisso e instrumentalizado. O estereótipo colhido ao vivo, no seu nascedouro. A cena é muito íntima, passa-se entre duas pessoas. Mas a mediação social, com os seus lugares-comuns, seus gestos cristalizados, sua face reconhecível, dão generalidade e impessoalidade ao poema. Existe toda uma história contida neste 'sim senhor doutor' e neste 'meu patrão'. Algo como a confirmação de um hábito, sua sedimentação, numa síntese de relacionamento onde tudo é transparente: o garçom é o garçom, o freguês é o freguês. Ambos têm os seus comportamentos e as suas falas respectivamente adequados à posição social de cada um. É de se notar o aspecto de transparência do poema: não há qualquer mediação retórica, o apego a qualquer automatismo estilístico, nada: a cena é mostrada ao vivo, diretamente, com economia de meios, apenas o suficiente que dê para o reconhecimento cordial da situação (Brito, 1997, p. 310-311).

O enunciado é exposto de maneira crua. De acordo com Cacaso, essa exposição sem mediação geraria inclusive um questionamento sobre a ideia de autoria. Explicando melhor: a começar pelo título, o poema funciona como um retrato; há um recorte de determinado diálogo que em sua situação enunciativa original nada teria de importante. Deslocado, contudo, começam a ter destaque as formas de tratamento como "meu patrão" e "doutor" e um diálogo aparentemente inocente vai mostrando o jogo de poder no diálogo entre garçom e cliente. Mostra também as estratégias do garçom que, como bem aponta Cacaso, "não se limita a ser correto: é solícito, além de velhaco".

No mesmo ensaio, há uma discussão sobre a relação arte e vida:

O poema curto dá a impressão, e há nisso um fundo de inverdade, de que é de fácil realização, abolindo as noções de competência e especialização literárias. E se postando, democraticamente, ao alcance dos pretendes. Quem é que não é capaz de registrar, sem compromisso e pretensão, qualquer coisa vivida ou observada, tudo ao sabor da ocasião e sem maiores delongas? Descobre-se que a poesia existe em tudo, e tudo pode ser poesia. É claro que, num momento desses, do ponto de vista da poesia em si mesma, é natural que haja um rebaixamento do nível de qualidade artística. Uma desqualificação da arte. Mas essa desqualificação vai ter um peso muito relativo e um valor tático, e em certo sentido passa a papel secundário. $\mathrm{O}$ impulso geral de desindividualização da autoria cumpria e cumpre uma função-chave, de alcance na poesia brasileira: a abertura para a experiência emergente, para a atualização da experiência (Brito, 1997, p. 324).

Algumas diferenças de postura em relação aos dois modernistas elencados ficam mais claras: há uma defesa da desindividualização, portanto não podemos aproximar Cacaso da defesa do lirismo e do aspecto psicológico tal como faz Mário de Andrade; por outro lado, essa desindividualização leva a uma defesa da abertura para a experiência, para a atualização da experiência, o que carrega uma subjetividade, portanto não se pretende objetiva como a poesia oswaldiana. A relação arte e vida em Cacaso chega a uma paradoxal defesa da subjetividade sem individualidade.

Trata-se da busca pela criação de um espaço discursivo de subjetividade. É uma prática da escrita que pode ser resumida na seguinte afirmação, do mesmo ensaio: "Do ponto de vista do poeta, o viver leva ao escrever; do ponto de vista do leitor, o ler leva ao viver" (Brito, 1997, p. 324).

A diferença entre Alvim e Chacal é que eles trabalham de formas diferentes com essa subjetividade desindividualizada. $\mathrm{O}$ primeiro busca no outro essa relação, o segundo cria um "eu" que, para falar com Flora Süssekind, "não é idêntico àquele dos depoimentos, biografias e memórias" (Süssekind, 1985, p. 127), ou seja, é também um "eu” desindividualizado.

Um último exemplo antes de chegar aos poemas do próprio Cacaso. Em um artigo sobre o poeta Charles Peixoto, destaca-se a seguinte afirmação, que vem confirmar algumas das leituras que propusemos até o momento:

O livro Creme de lua, a começar pelo título e pelo desenho da capa, participa deste tipo especial de romantismo que já não crê em si mesmo, que sabe que suas imagens estão desgastadas, que sua aura está em estado avançado de decomposição, e que uma atitude nova está sendo exigida. Ora, desde o momento em que o poeta perde o interesse pela forma fixa e estereotipada, pelo jargão poético já legitimado, apenas uma atitude pode 
reconduzi-lo a uma consistente renovação de sua capacidade expressiva: voltar a frequentar a matéria densa e complexa da experiência vivida por ele e seus contemporâneos (Brito, 1997, p. 217).

Mais uma vez vemos a combinação entre a poesia e vida para dar liberdade ao poeta. Importante marcar aqui, mais uma vez, a diferença entre Cacaso e os modernistas. A poesia deve buscar sempre o "direito de errar", ou seja, a liberdade de experimentação, também defendida por Mário, mas que no modernista não leva à autonomia da arte, pelo contrário, acabou por exigir, em suas últimas palestras e ensaios, um engajamento do artista.

A procura por elementos de comunicabilidade, da renovação da capacidade de expressão sem que se perdesse o movimento crítico, pelo "direito de errar" aparecia também em textos poéticos de Cacaso. Em nossa leitura, essa busca por uma poética mais "solta", que foge da institucionalização é gradual e não é regular. Ou seja, há um aprofundamento nessa busca de uma obra para outra, mas isso não significa que todos os poemas de um livro como Beijo na boca, em nossa opinião aquele que melhor mostra esse lado de Cacaso, se adequem a esse tipo de poética.

A relação com os modernistas aparece também na obra poética. Um exemplo interessante desse diálogo pode ser retirado do livro de 1978, o já mencionado Na corda bamba:

Façanha

Tomou muita cachaça

Ficou lúcido

Quis se matar (Brito, 2002, p. 65)

Em um primeiro momento não há muito o que falar do poema, parece retratar uma situação quase banal de um homem bêbado que quer se matar. Não sabemos qual a origem da história, se ela é inventada, se ela foi ouvida, se ela foi lida em um jornal. Narrada de forma simples e direta, a história é completamente impessoal, sendo contada em terceira pessoa, sem referências espaciais. Poderíamos deduzir que se trata de uma pessoa de classes sociais mais baixas, pois toma cachaça e não whisky. Ainda assim, não é uma afirmação que possa ser feita de forma categórica, pois senhores de engenho também bebem suas cachaças. Não sabendo se é um ambiente rural ou urbano, se é em uma capital ou em uma pequena cidade, se é um paulista, um baiano ou um carioca, pouco podemos afirmar sobre o sujeito que se desenha no poema.

A banalidade do poema é reforçada pela sua descartabilidade. Certamente não é um grande poema de Cacaso e sua força reside justamente no fato do retrato sem mediação alguma, o qual, diferente do que ocorre com Alvim, não constrói um movimento crítico, posto que se fecha em si mesmo. Há uma necessidade de despoetização nesses versos que parece forçada.

Em um segundo momento, contudo, podemos parar e encontrar semelhanças com outro poema. Podemos abrir um livro de um poeta pernambucano modernista e encontrar o seguinte título: "Poema tirado de uma notícia de jornal". O poema é bastante famoso, mas cabe reproduzilo para reforçar que o leitor ele próprio note a semelhança:

Poema tirado de uma notícia de jornal

João Gostoso era carregador de feira livre e morava no morro da Babilônia num barracão sem número]

Uma noite ele chegou no bar Vinte de Novembro

Bebeu

Cantou

Dançou

Depois se atirou na lagoa Rodrigo de Freitas e morreu afogado (Bandeira, 2007, p. 135).

É de Bandeira o poema. E as diferenças entre este e o de Cacaso são tão visíveis quanto as semelhanças. As referências espaciais, se não definem o personagem, dão a ele uma individualidade: sabemos que ele era chamado de "João Gostoso", morava no morro da Babilônia, embebedou-se no bar Vinte de Novembro e morreu na lagoa Rodrigo de Freitas, morador do Rio de Janeiro, portanto. A diferença principal, contudo, está no título. Davi Arrigucci Jr. faz o seguinte comentário sobre o poema: 
A força simbólica do achado de Bandeira, que com ele arrasta o bloco de uma realidade muito mais ampla e complexa, demonstra a autonomia da forma significativa obtida pelo poema, ao desvencilhar-se do jornal e do caráter circunstancial da notícia de onde se originou (Arrigucci Jr., 2001, p. 108).

Certamente há uma autonomia da forma poesia, embora possamos questionar se o texto se desvencilha de fato do jornal, posto que no título há o anúncio de onde se buscou a matéria-prima. Anuncia, ainda, que sua intenção é poetizar aquela matéria bruta que não poderia, em si, ser poesia. O texto está para sempre ligado à forma jornalística, pois essa relação é estabelecida no título.

Não seria demais dizer que Cacaso buscou esse poema como ponto de partida para seu próprio poema, fazendo o movimento de busca da matéria-prima. Heloísa Buarque, em entrevista publicada na revista Inimigo rumor, expõe o seguinte aspecto sobre o mineiro e sua relação com os modernistas:

Para responder especificamente sua última pergunta: Cacaso, no maior rigor, estudava sim e seríssimamente cada um dos modernistas separadamente, especialmente Bandeira, seu predileto, sobre o qual tinha análises e insights sapientíssimos (Hollanda, 2000, p. 102).

Começa a se desenhar a diferença entre a postura diante da escrita que Cacaso exerce e aquela exercida pelos modernistas. O poeta avança mais um passo na trajetória iniciada por Bandeira. Perde-se a necessidade de objetivar a matéria cotidiana, algo que ocorre tanto em Bandeira quanto em Oswald, e em outros poetas modernistas, mesmo que se corra o risco de torná-la inócua. A poesia quando livre pode tornar-se livre até da escrita ela mesma. Assim pensava Cacaso.

Lendo um poema de Cacaso, podemos perceber com mais clareza essas diferenças de postura que aparecem em um poema do livro Grupo escolar, de 1974:

Jogos florais

I

Minha terra tem palmeiras

onde canta o tico-tico.

Enquanto isso o sabiá

vive comendo o meu fubá.

Ficou moderno o Brasil

ficou moderno o milagre:

a água já não vira vinho,

vira direto vinagre.

II

Minha terra tem Palmares

memória cala-te já.

Peço licença poética

Belém capital Pará.

Bem, meus prezados senhores

dado o avançado da hora

errata e efeitos do vinho

o poeta sai de fininho.

(será mesmo com 2 esses

que se escreve paçarinho?) (Brito, 2002, p. 157)

O movimento crítico do poema resulta da combinação de um diálogo com situações enunciativas distintas, deslocadas de seu contexto original e a referência ao cotidiano, passando, neste texto em específico, pela citação histórica. As referências passam por Gonçalves Dias e Oswald de Andrade, o "milagre econômico" brasileiro e a bíblia.

O título do poema também ele é uma referência: remete a uma competição de trovas, poemas compostos de estrofe de quatro versos, todos em redondilha maior, com rimas cruzadas ou alternadas. Há, no entanto, uma subversão da forma: a trova é apenas de uma estrofe, teríamos, portanto, quatro trovas e não duas. Além disso, a última estrofe tem apenas dois versos, quebrando a estrutura em quadras; o fato dela aparecer entre parênteses indica uma espécie de adendo, um complemento ao que já foi dito. 
A divisão do poema em duas partes corresponde a uma mudança no tom. Se a citação que abre a primeira parte é de um famoso poema celebratório, a "Canção do exílio", do poeta romântico Gonçalves Dias, a presença marcante na segunda parte é Oswald de Andrade, o poeta modernista, ainda que em releitura da poesia de Gonçalves Dias, que é a referência principal, percorrendo todo o poema.

A ideia de exílio, na primeira parte, ganha outra dimensão quando retomada nos anos $1970 \mathrm{em}$ plena ditadura, perdendo o tom saudosista e ganhando um tom melancólico. O texto romântico é usado para criticar, pois o sabiá, metáfora para o Brasil, come toda comida do tico-tico, retomando a figura do povo. Estende-se a crítica com a ajuda de referências bíblicas: a famosa passagem quando Jesus transforma a água em vinho, realizando um milagre, é usada para criticar o "milagre econômico" dos anos 1970 que de milagroso não teria nada; por mais moderno que seja, esse milagre, quando do momento da partilha, já é vinagre, ou seja, na divisão das riquezas geradas pelo avanço da economia brasileira, fica para a população a parte "estragada" do vinho, o vinagre. ${ }^{7}$ É o que se convencionou chamar de modernização conservadora. $O$ futuro não aparece de forma esperançosa, pelo contrário, reforçada pela melancolia do exílio causado pelo golpe, há uma promessa que, sempre anunciada, não se cumpre. A irreverência de Cacaso funciona tanto em seu sentido mais usual, de comicidade, quanto na ausência de reverência.

Ainda quanto às referências românticas e ao texto de Gonçalves Dias, os versos são redondilhas maiores, com dois versos em oitava. Os versos em redondilha remetem tanto a cultura popular, quanto a cultura escrita, no caso as trovas a que faz referência o título: "jogos florais" são uma competição de trovas, poemas de apenas uma estrofe, sempre de quatro versos heptassílabos com rimas cruzadas ou alternadas. As trovas de Cacaso não são todas elas escritas de acordo com o bom manual de versificação; deveriam ser quatro e não duas como indicam os números acima dela para que fossem monoestróficas, há dois versos de oito sílabas e as rimas não seguem um padrão. Essa referência, trazida pelo título, a uma forma fixa que no decorrer do poema não encontra sua confirmação é outra maneira de descumprir as promessas anunciadas.

Na segunda parte, que começa com uma referência a Oswald, o tom aproxima-se ainda mais do coloquial, como que seguindo as lições modernistas. Se na primeira parte é o futuro que nunca se cumpre, na segunda parte é a memória que não pode ser resgatada. Há, contudo, uma contradição performativa, uma contradição que parece ser própria do período: a memória não pode ser resgatada, no entanto ela já foi enunciada, ou seja, ela já foi resgatada. A relação entre autonomia e repressão, tão tensa neste poema, parece ser uma característica constitutiva do período ditatorial no Brasil, algo já explorado por Roberto Schwarz em famoso ensaio. Ainda mais interessante é a maneira com que a repressão aparece: na forma de um aluno bem-comportado e exemplar, que, pedindo licença (poética, é bem verdade), enuncia, orgulhoso, a capital do Pará. Poderia ser mais uma crítica ao academismo vazio que tanto horror causava em Cacaso.

Essa aproximação tensa entre autonomia e repressão reaparece no contraste entre a cultura letrada e a cultura oral, que também percorre todo o poema, seja na referência aos românticos e aos modernistas, a Bíblia e ao milagre econômico, à escola e ao quilombo, e explode na última estrofe. Ao se questionar se passarinho é com dois esses, escrevendo "paçarinho", com cedilha, a relação entre fala e escrita ganha nova dimensão. É quebrada a preeminência da cultura escrita, restando a ela o questionamento. Contudo, não é possível fazer a afirmação de que a cultura oral sai vencedora, já que o poema só existe como materialidade por meio da escrita. Mais uma vez, Cacaso joga com uma tensão não resolvida.

Esta parece-nos ser a característica marcante do período, afetando diretamente a produção marginal. Eles têm de lidar com um embate entre a poesia engajada do CPC e seu Violão de Rua e a poesia de vanguarda dos concretos e neoconcretos. Têm de lidar com um campo que apresenta características de um campo autônomo, mas ainda sofre com a repressão. Lidam com um

\footnotetext{
${ }^{7} \mathrm{O}$ vinagre também é uma referência comum sobre a cena da crucificação. Em dois momentos oferecem a Jesus o vinagre: primeiro, o vinho com mirra, ou vinagre com mirra dependendo da tradução, que serviria para aplacar as dores, uma espécie de anestésico; no segundo momento, já na cruz, Jesus tem sede e soldados embebem uma esponja em vinagre para lhe darem de beber. É neste segundo momento, depois de beber vinagre, que Jesus diz "está consumado". A referência ao vinagre, portanto, também traz a imagem simbólica de algo consumado, sem possibilidade de volta. Agradeço aos pareceristas pela referência a essa passagem bíblica.
} 
mercado editorial já constituído, mas com a dificuldade de fazer circular suas obras. Há reflexos de todas essas questões nos melhores textos marginais.

Como consequência, temos o que viemos chamando de rarefação da escrita. Isso não significa que o texto perca força em sua materialidade ou que haja uma predominância da fala sobre a escrita nos poemas de Cacaso. Há um processo que faz do poema uma espécie de instância privilegiada das contradições diversas do período que apontamos até aqui. Utilizados como lados de uma mesma moeda, e não como armas em um confronto, expressão e construção, fala e escrita, liberdade e repressão, arte e vida tornam-se ferramentas críticas importantes, marca de grandes escritores, em especial grandes poetas, em diferentes épocas. Cacaso dá outra função a esse trânsito, mostrando os limites da criação. Pondo em xeque concepções sobre a poesia, ele constrói um espaço discursivo no qual há espaço para a voz, mas ela prefere se calar ou colocar afirmações que nunca são derradeiras, promessas que não se cumprem, situações enunciativas que são familiares ao leitor, mas que criam um novo sentido.

A rarefação da escrita é a junção dessas possibilidades, algo que ocorre nos bons poemas

de Cacaso. É essa constante ressignificação, por meio de ferramentas das mais variadas, que faz com que, paradoxalmente, como não poderia deixar de ser, o discurso ganhe força, quando o lastro maior de qualquer discurso, o corpo, já não está sob os domínios do sujeito. A liberdade de criar, na sua teorização marioandradina e em seu fazer oswaldiano, é o que sustenta a prática de Cacaso. No entanto, a historicidade específica do poeta mineiro direciona para uma radicalização da instabilidade. Criam-se espaços discursivos, algo que todos os bons poetas marginais fizeram, mas nunca é possível preenchê-los por completo. É como se a função-sujeito criada pela poesia marginal fosse um espaço que se deixa sempre vazio, um corpo que não se pode controlar, pois não pertence a ninguém.

\section{Referências}

ALVIM, Francisco (1988). Poesia reunida. São Paulo: Duas cidades.

ANDRADE, Mário de (1963). O baile das quatro artes. São Paulo: Martins Fontes.

ANDRADE, Mário de (1978). Aspectos da literatura brasileira. São Paulo: Martins Fontes.

ANDRADE, Mário de (1980). Obra imatura. São Paulo: Martins Fontes; Belo Horizonte: Itatiaia.

ANDRADE, Oswald de (1972). Poesias reunidas. Rio de Janeiro: Civilização Brasileira.

ANDRADE, Oswald de (1997). Manifesto Pau-Brasil. In: TELLES, Gilberto Mendonça. Vanguarda européia e modernismo brasileiro. Petrópolis, RJ: Vozes. p. 326-331.

ARRIGUCCI Jr, David (2001). Humildade, paixão e morte: a poesia de Manuel Bandeira. São Paulo: Companhia das Letras.

BANDEIRA, Manuel (2007). Estrela da vida inteira. Rio de Janeiro: Nova Fronteira.

BRITO, Antônio Carlos de (Cacaso) (1975). Beijo na boca. Rio de Janeiro: Edição do Autor.

BRITO, Antônio Carlos de (Cacaso) (1978). Na corda bamba. Rio de Janeiro: Edição do Autor.

BRITO, Antônio Carlos de (Cacaso) (1997). Não quero prosa. Campinas: Editora da Unicamp; Rio de Janeiro: Editora da UFRJ.

BRITO, Antônio Carlos de (Cacaso) (2000). Beijo na boca. São Paulo: 7Letras.

BRITO, Antônio Carlos de (Cacaso) (2002). Lero-lero. São Paulo: Cosac \& Naify.

CAMPOS, Haroldo de (1971). Uma poética da radicalidade. In: ANDRADE, Oswald de. Poesias reunidas de Oswald de Andrade. Rio de Janeiro: Civilização Brasileira. p. 9-62.

DANTAS, Vinicius (1991). A poesia de Oswald de Andrade. Novos estudos, São Paulo, v. 2, n. 30, p. 191-203, jul. 1991. 
DANTAS, Vinicius; SIMON, Iumna. Poesia ruim, sociedade pior. Novos estudos, São Paulo, v. 2, n. 12, p. 4861, jun. 1985.

HOLLANDA, Heloísa Buarque (2000). Entrevista com Heloísa Buarque de Hollanda. Inimigo rumor, Rio de Janeiro, n. 8, p. 98-110, mai. 2000.

HOLLANDA, Heloísa Buarque (2002). Entrevista com Charles Peixoto sobre Cacaso. Disponível em: <https:/ / bit.ly/2U7q2BH>. Acesso em 25 jan. 2018.

LAFETÁ, João Luiz (2000). 1930: a crítica e o modernismo. São Paulo: Duas Cidades; Editora 34.

SCHWARZ, Roberto (1965) O psicologismo em Mário de Andrade. In: SCHWARZ, Roberto. A sereia e o desconfiado. São Paulo: Duas cidades.

SCHWARZ, Roberto (1987). A carroça, o bonde e poeta modernista. In: SCHWARZ, Roberto. Que horas são? São Paulo: Companhia das Letras.

SCHWARZ, Roberto (2002). No país do elefante. Folha de S. Paulo, São Paulo, Caderno Mais!, p. 6, 10 mar. 2002.

SÜSSEKIND, Flora (1985). Literatura e vida literária: polêmicas, diários e retratos. Rio de Janeiro: Jorge Zahar. 